\title{
REFLECTION
}

\section{Today I'm Grieving a Physician Suicide}

\author{
Jennifer L. Middleton, MD, MPH
}

Department of Family Medicine, University of Pittsburgh, Pittsburgh, Pennsylvania

\begin{abstract}
An estimated 250 physicians will commit suicide this year. In this essay, the author shares her grief and guilt over the suicide of a colleague while reflecting on both the scale of this largely unacknowledged problem and the stigma that prevents our profession from adequately addressing it. Physicians are as vulnerable to depression as is the general population, but they seek care at lower rates and commit suicide at higher rates. Fears regarding loss of professional stature and respect often prevent depressed physicians from accessing needed mental health services. This same stigma can also compound the mourning process of the colleagues and family of those physicians who complete suicide. As a profession, physicians must strengthen existing resources for impaired colleagues and work collaboratively to destigmatize treatment for mental illnesses.
\end{abstract}

Ann Fam Med 2008;6:267-269. DOI: 10.1370/afm.840.

$\mathrm{T}$ Today I learned that you died, and nothing will ever be the same again. I refused to believe the words I heard, that you committed suicide. Only terribly depressed people kill themselves. You weren't terribly depressed ... but then I learned that, yes, secretly you had been. How could I not know, not realize?

Your body will be laid to rest in 3 days. My body doesn't seem to belong to me anymore-it walks and talks, it swallows food and gets in the shower, but it's as if my mind has flown above it so that I can't feel the gut-wrenching agony threatening to consume me.

Why didn't you ask your physician colleagues for help? Why did you hide your depression from us? Did I, as your colleague and friend, fail you? These questions circle relentlessly through my mind. I need to understand, need somehow for this all to make sense.

$$
* * * * *
$$

Today I'm struggling with the awkward conversations regarding your death. "I would have helped if I had only known," so many said. Did you fear losing the respect of your colleagues and coworkers if they had indeed known? The culture of medicine demands that physicians suppress vulnerability or need ${ }^{1,2}$ and this ethos does not accept help-seeking behavior. ${ }^{2}$ A recent JAMA Consensus Statement concluded that the stigma against physicians with depression is a strong disincentive for obtaining treatment. ${ }^{1}$ I worry that this "macho mentality"2 of medicine may have dissuaded you from confiding your suicidal thoughts in anyone.

I knew you as both my colleague and my friend. Your spirit is still the most generous and insightful I have ever known. Your smile was bright and full of compassion. You shared your opera tickets with me and listened simply to my insecurities. You brought a bakery cake and candles to my birthday dinner at a local restaurant last year and led the table in singing to me.

Everyone keeps asking whether I'm okay. What am I supposed to say? I lie most of the time. I figure that they would rather hear platitudes than the truth. The bitterly frigid vestiges of winter's finale cut into my coat 
and pierce my skin. Everything is too bright, too cold, too sterile.

$$
* * * * *
$$

Today I learned the details of your death. I thought about writing them here; I want to see the words blazing out at me. I want the page to groan from the pain of your last days and hours. I want it to cry out, "Enough! How can we let this keep happening?"

I realized, however, that it does keep happening. Depression is as common among physicians as it is in the general population, and we commit suicide at higher rates. ${ }^{1-6}$ Some of that difference may be explained by both our knowledge about and our access to lethal means, ${ }^{4}$ but that explanation is incomplete. Overall, most doctors hesitate to address depression in both themselves and their colleagues. ${ }^{1}$ This fact is unsurprising considering how our professional culture stigmatizes depression. A physician who survived a suicide attempt asked, "Do we as doctors accept depression as a treatable medical illness-as long as the patient isn't one of us?"7 I choose to reject any assertion that your death was the result of some fundamental weakness or personality flaw I see no dishonor in either the manner of your death or of the disease process that led you there.

The JAMA Consensus Statement on physician depression and suicide was published in 2003, almost 4 years before you died. What, if anything, has changed in that time? I am frustrated by our profession's resigned acceptance of your death. Individually, we wring our hands in frustration and wonder how we might have intervened, but collectively I see no concerted effort to address this problem. I feel alone in my indignation and anger.

$$
* * * * *
$$

Today I tasted food for the first time since your death. It's as though my mind has gotten brave enough to exist inside my body again. I can feel the rebound of the keys as I type, can hear the quiet hum of the desk lamp's bulb beside me. I keep the television on, barely loud enough to hear, its delicate river of noise flowing behind me. I need those dim, purposeless amplitudes, need anything more than just my thoughts for company; it's too unbearable to cycle through my memories and the pieced-together imaginings of your final day.

I wonder whether we, whether I, missed the signs of your impending suicide. Studies in the 1970s and 1980s described the physician at high risk of suicide as driven, competitive, and compulsive ${ }^{1,2}$; having few friends ${ }^{2}$ and no spouse ${ }^{1}$; and, most importantly, having a history of depression or substance abuse. ${ }^{1,2,4}$ You were certainly hard working and diligent, but those traits hardly distinguish you from most other physicians. You had a sizable social network. You were receiving mental health care before you died, but few of us surrounding you knew, as you did not disclose your depression diagnosis to anyone but your closest friends and family. I am left contemplating what share of the responsibility, of the guilt, should be mine.

Sleep remains elusive for me, nothing more than short intervals of dreamless stupor interspersed with endless stretches of the clock face's screaming inanity. Did you sleep the night before you died?

$$
* * * * *
$$

Today a visiting lecturer commented that 250 physicians commit suicide every year in the United States. ${ }^{6}$ Hearing that number knocks the breath out of me. Two hundred fifty souls who will lose their battle with the dark, cognitive distortions of depression. Two hundred fifty populations of families, classmates, friends, and colleagues whose lives will be forever scarred.

How many others in my life are suffering silently, as you did? I thought I knew you, understood you, but clearly I didn't really know you at all. My intuition will now be forever suspect. I realize that I have been scripting the lives of those around me according to my own understandings and experiences instead of allowing their unique truths to touch me.

I'm less concerned with getting to the diagnosis and plan in my patient encounters now, as I'm suddenly much more interested in my patients' stories. I find myself listening more intently to what they say to me, searching for clues to their words' intended meaning, prompting them to share more. I have always wanted to ease suffering as a physician, but I never understood what the depths of that suffering could be before. I do not think that my treatment goals themselves have changed, but I hope that my interactions with patients now express better the depths of my concern for them and my genuine desire to understand them as individuals.

$$
* * * * *
$$

As the months have passed, the acute pain of your loss has dulled, but the questions remain. Why didn't you ask for help? Why did you hide your depression? Did I, as your colleague and friend, fail you? Despite my exploration of the literature, I can still only speculate at the answers. I have no doubt, however, that we cannot continue to neglect the issue of physician suicide.

Two hundred forty-nine other physicians will commit suicide this year. This number indicates no less than an ongoing crisis, yet I have found that few researchers have studied physician suicide, and what little literature does exist is mostly outdated. ${ }^{1,2}$ 
Increasing attention to this devastating problem may encourage dialog among physicians, perhaps decreasing the shame surrounding our mental health issues and creating collaboration to find solutions. All of us as physicians also have a responsibility to contribute to a professional culture that, instead of stigmatizing and isolating, is instead affirming and supportive.

I wonder how many more physicians' lives will be lost before we confront this silent crisis of depression and suicide in our profession; I can only wish that we might start today.

To read or post commentaries in response to this article, see it online at http://www.annfammed.org/cgi/content/full/6/3/267.

Submitted August 27, 2007; submitted revised February 10, 2008; accepted February 16, 2008.

Key words: Suicide; physicians; psychosocial issues in health care; social support; mental health/depression; depressive disorder; behavioral medicine
Acknowledgments: The author also wishes to acknowledge the kind assistance of Ms Joann Buckley, Jonathan Han, MD, and Joel Merenstein, MD.

\section{References}

1. Center C, Davis M, Detre T, et al. Confronting depression and suicide in physicians: a consensus statement. JAMA. 2003;289(23): 3161-3166.

2. Miller NM, McGowen RK. The painful truth: physicians are not invincible. South Med J. 2000;93(10):966-973.

3. Torre DM, Wang NY, Meoni LA, Young JH, Klag MJ, Ford DE. Suicide compared to other causes of mortality in physicians. Suicide Life Threat Behav. 2005;35(2):146-153.

4. Black D. When physicians commit suicide. lowa Med. 1992;82(2): 58-61.

5. Victoroff VM. My dear colleague: are you considering suicide? JAMA. 1985;254(24):3464-3466.

6. Hendin H, Maltsberger JT, Haas AP. A physician's suicide. Am J Psychiatry. 2003;160(12):2094-2097.

7. Eilers GM. I was a success at everything-except suicide. Wis Med J. $1996 ; 95(4): 223-225$. 